\title{
Effects of Melt Vibration During Solidification on the Mechanical Property of Mg-Al-Zn Alloy
}

\author{
Aramide Fatai Olufemi ${ }^{1, *}$, Ibitoye Simeon Ademola ${ }^{2}$ \\ ${ }^{1}$ Metallurgical ,Materials Engineering Department, Federal University of Technology, Akure, Ondo State, Nigeria \\ ${ }^{2}$ Materials Science, Engineering Department, Obafemi Awolowo University, Ile-Ife, Osun State, Nigeria
}

\begin{abstract}
The effect of mechanical mould vibration during melt solidification on the mechanical properties of an AZ91 magnesium alloy was investigated. This was tested in the frequency range from 0 to $24 \mathrm{~Hz}$ and at two vibration intensities; $5 \mathrm{~V}$-peak to peak and 10V-peak to peak. Mechanical tests such as tensile test, hardness test and impact test were carried out on the samples. Improvements were observed in the mechanical tests within the frequency threshold of $12 \mathrm{and} 16 \mathrm{~Hz}$. It was concluded that vibration of moulds during melt solidification have some refining effects on the grain structures of the alloy and improve the mechanical properties of the sample. The optimum frequency of mold vibration is between $12 \mathrm{and} 16 \mathrm{~Hz}$.
\end{abstract}

Keywords Mould Vibration, AZ91 Magnesium Alloy, Solidification, Melt

\section{Introduction}

Materials (metallic) whose microstructure have been subjected to grain-refinement possess many advantages which among others include, good mechanical properties $[1$, 2], thermal stability[3] and low temperature and/or high strain rate superplasticity[4]. This grain refinement can be achieved either when external forces are applied to induce fluid flow during solidification which include rotation of the mold, mechanical/electromagnetic stirring of melt and rheocasting $[5,6]$ or by imposing very large plastic strains through several techniques which include, multiaxial Forging[7], accumulative roll-bonding[8] and equal-channel angular pressing (ECAP) [9].

Grain refinement is a spontaneous transition observed in many pure metals and alloys above a critical undercooling, $\Delta \mathrm{T}^{*}$. The coarse columnar grain structure evident below $\Delta \mathrm{T}^{*}$ is replaced by a equiaxed structure. The transition is accompanied by a break in the growth velocity-undercooling curve and a change in the shape of the solid-liquid interface from angular to smooth[10].

In most foundry in this country, alloys are normally subjected to annealing in order to impart workability in to them; this research endeavour is aimed at investigating the possibility of improving workability of these alloys during solidification, for all applications involving plastic deformation of the cast alloy without necessarily subjecting it to annealing.

* Corresponding author:

fat2003net@yahoo.com (Aramide, Fatai Olufemi)

Published online at http://journal.sapub.org/ijmee

Copyright (C) 2012 Scientific \& Academic Publishing. All Rights Reserved

\section{Materials and Methods}

The materials used for this research are Magnesium alloy, Aluminum alloy (whose composition is shown in the Appendix) and Zinc metal of $99.98 \%$ purity. From these, the charge calculation was made to arrive at alloy composition $90 \% \mathrm{Mg}, 9 \% \mathrm{Al}$ and $0.6 \% \mathrm{Zn}$. Other materials used for this work are flux $\mathrm{MgCl}_{2} \cdot \mathrm{KCl} . \mathrm{H}_{2} \mathrm{O}$ and $\mathrm{MgO}$ used during melting to coagulate and separate the slag from the melt.

A vibrator device which converts electrical signals to mechanical vibrations was coupled to the target moulds. This vibrator produced horizontal vibrations.

The melt was produce in a cast iron crucible placed in an electric furnace, after charging it with $90 \%$ Magnesium sample, 9.2\% Aluminum (6063) sample and $0.6 \%$ zinc sample. The salt based flux $\left(\mathrm{MgCl}_{2} \cdot \mathrm{KCl} . \mathrm{H}_{2} \mathrm{O}\right.$ and $\left.\mathrm{Mg} 0\right)$ was added to it to coagulate slag and de-slag the melt. The electric furnace was set at $850{ }^{\circ} \mathrm{C}$ and then switched on. The first melt was poured into non-vibrating permanent moulds. While the subsequent melt was poured into permanent moulds being vibrated at varied frequencies. (The vibration was brought about using two different vibration intensities of 5 volt peak to peak and 10 volts peak to peak).

The cast rods were machined to standard dimensions for the impact and tensile test samples on a lathe machine.

\subsection{Tensile Testing}

The tensile tests were performed on various samples using Monsanto tensometer. The fracture load for each sample was noted as well as the diameter at the point of fracture and the final gauge length. The initial diameter and initial gauge length for each sample was noted before uniaxial load. From 
the generated data the ultimate tensile strength and percentage elongation of each sample were calculated.

\subsection{Impact Test}

The impact tests were performed on various sample determine the impact strengths by the "V-notch method using the Honsfield Balance Impact Testing Machine. Prior to mounting on the machine, the test sample is notched to a depth of $2 \mathrm{~mm}$ with v-shaped hand file. The notched test sample was then mounted on the impact-testing machine, which was then operated to apply a (constant) impact force on the test sample. The impact strength (the amount of impact energy the specimen absorbed before yielding) was then read off the calibrated scale on the impact testing machine.

\subsection{Hardness Test}

The hardness test was carried out on the various test sample using the Hounds Field Tensometer with a compression die and the Brinell ball bolster attached, having adjusted the mercury level to zero.

Two samples each of the various test samples were initially grounded to 600 microns, and then polished using the Ecomet II machine to produce smooth and shining surfaces. The polished surface of each sample was held against the Brinell ball and the load was applied until the mercury level read $125 \mathrm{KN}$, this was allowed to be in place for 15 seconds. The diameter of the impression left by the ball on the sample was measured using the Brinell calibrated hand lens and the corresponding Brinell hardness numeral was determined.

\section{Results and Discussion}

Table 1 shows the results obtained from the various test carried out on various samples of the Mg-Al-Si alloy. While figures 1, 2, 3 and 4 depicts the relationship of the ultimate tensile strength, percentage elongation, Brinells hardness number and absorbed energy of the alloy respectively with the frequency of vibration of the mould contain the molten alloy until solidification was complete.

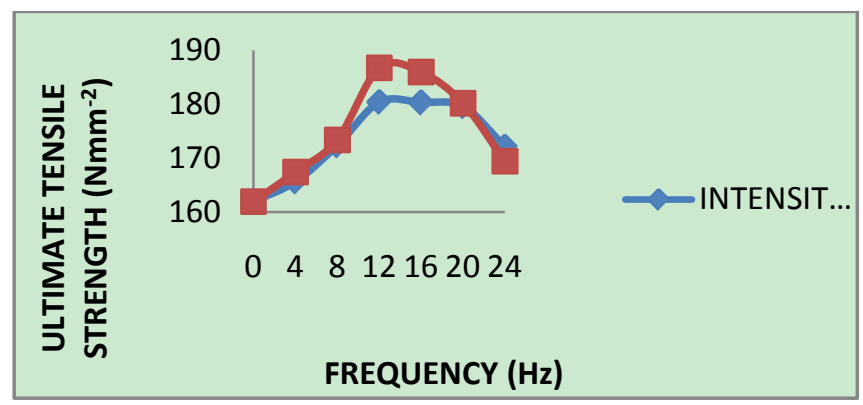

Figure 1. Relation between the Frequency of vibration and Ultimate Tensile Strength of the samples

Figure 1 reveals that the ultimate tensile strength (UTS) for the two sets of samples (Intensity 1; $5 \mathrm{v}$ peak to peak and
Intensity 2; $10 \mathrm{~V}$ peak to peak) increases with increase in the frequency of vibration until maximum value is attained between 12 and $16 \mathrm{~Hz}$. The value of the UTS then decreases with further increase in the frequency of vibration. It could also be observed that the value of UTS is higher for the samples with intensity 2 between zero and $24 \mathrm{~Hz}$ frequency of vibration and lower than that of intensity 1 from between 20 and $24 \mathrm{~Hz}$. This could be explained as, intense stirring changes dendrite to globular formation[11]. Also, Mollard et at,[12] have demonstrated that sonic or ultrasonic vibrations of mechanical origin are effective in increasing fluidity by as much as a factor of three. Moreover, vibrations promote partial desorption of gases that could have resulted into casting flaws which would have drastically affected the UTS of the samples[13]. In Figure 1, the samples with no vibration had the lowest UTS, this is due to the absence of shear, the solidification of the samples occurred by forming dendrites, there will be virtually no globular structure in the micrograph. The dendritic structure tends to have sharp-edged rims which introduce region of stressconcentration[14]. It is observed that initially the UTS increase with the frequency vibration till maximum UTS is reached. It thereafter dropped in value with further increase in the frequency of mould vibration. This is because shearing effects of the mould vibration breaks dendritic particles and deforms into a spheroidal (globular) shape[5, 15, 6]. Both the intensity and frequency of mould vibration have some effects on the fineness of the globules formed; the higher the frequency the finer the globules (spheroidal particles) formed. This is why the UTS is observed to increase with frequency of mould vibration to a certain threshold (12 -16 $\mathrm{Hz}$ ) where maximum UTS is recorded.

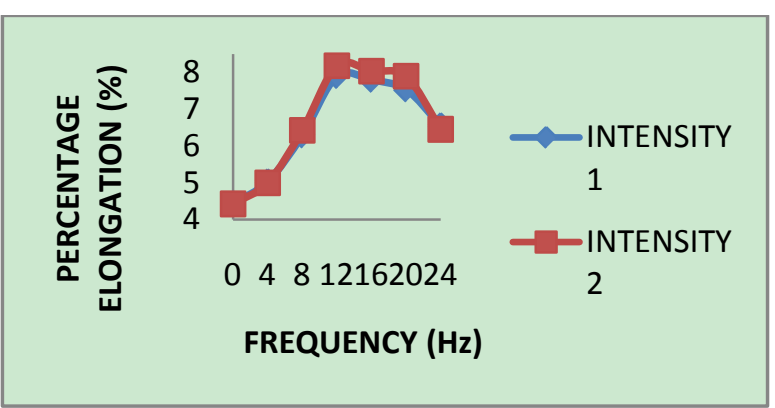

Figure 2. Effects of Frequency of vibration on the Percentage Elongation of the samples

Figure 2 depicts the effects of frequency of vibration of the mould during pouring till completion of solidification on the percentage elongation of the samples; it could be observed that the frequency of vibration of the mould during melt pouring affects the percentage elongation of the samples. Samples with no vibration have the least percentage elongation for the two sets of sample (4.4252\% elongation). The percentage elongation reaches the maximum at around $12 \mathrm{~Hz}$ and then begins to decrease with further increase in the frequency. It is also observable that the intensity of vibration also has some level of influence on the ductility of the samples both in Figures 1 and 2. 
Table 1. Results of various Mechanical Properties at different Frequencies of Mould Vibration

\begin{tabular}{|c|c|c|c|c|c|c|c|c|}
\hline $\begin{array}{c}\text { Frequency of } \\
\begin{array}{c}\text { Vibration } \\
(\mathrm{Hz})\end{array}\end{array}$ & \multicolumn{4}{|c|}{ Vibration Intensity 1 } & \multicolumn{5}{c|}{ Vibration Intensity 2} \\
\cline { 2 - 10 } & $\begin{array}{c}\text { UTS } / \mathrm{mm}^{2} \\
\text { Elongation }\end{array}$ & BHN & $\begin{array}{c}\text { Impact } \\
(\mathrm{J})\end{array}$ & $\begin{array}{c}\text { UTS } \\
\mathrm{N}^{2} \mathrm{~mm}^{2}\end{array}$ & $\begin{array}{c}\% \\
\text { Elongation }\end{array}$ & BHN & $\begin{array}{c}\text { Impact } \\
(\mathrm{J})\end{array}$ \\
\hline 0 & 161.9113 & 4.4262 & 27.2273 & 37 & 161.9113 & 4.4262 & 27.2278 & 37 \\
\hline 4 & 165.6139 & 5.0260 & 29.6827 & 38.5 & 167.4256 & 5.0000 & 32.4804 & 40.4 \\
\hline 8 & 172.3213 & 6.2814 & 35.6827 & 41.2 & 173.3691 & 6.4236 & 35.6872 & 43.4 \\
\hline 12 & 180.3809 & 7.8947 & 35.6872 & 43.4 & 186.7255 & 8.1811 & 35.6872 & 47.1 \\
\hline 16 & 180.2846 & 7.7966 & 35.6872 & 43.1 & 185.9374 & 8.03287 & 35.6872 & 40 \\
\hline 20 & 179.5737 & 7.5306 & 29.6827 & 38 & 180.1724 & 7.89473 & 27.2273 & 39 \\
\hline 24 & 172.1505 & 6.5630 & 27.2273 & 38 & 169.4286 & 6.4516 & 27.2273 & 39 \\
\hline
\end{tabular}

Figure 3 presents the effects of frequency of vibration of the mould during pouring on the Brinells Hardness number of the samples. It is conspicuously revealed that the hardness of samples increases with the frequency of vibration, reaches the maximum between 9 and $16 \mathrm{~Hz}$ and then begins to fall to the minimum. It is also observable that the hardness of the intensity 2 samples was more than that of intensity 1 samples between 0 and $8 \mathrm{~Hz}$, becomes the same between 8 and $16 \mathrm{~Hz}$ and the lower than those of the intensity 1 samples between 16 and $24 \mathrm{~Hz}$.

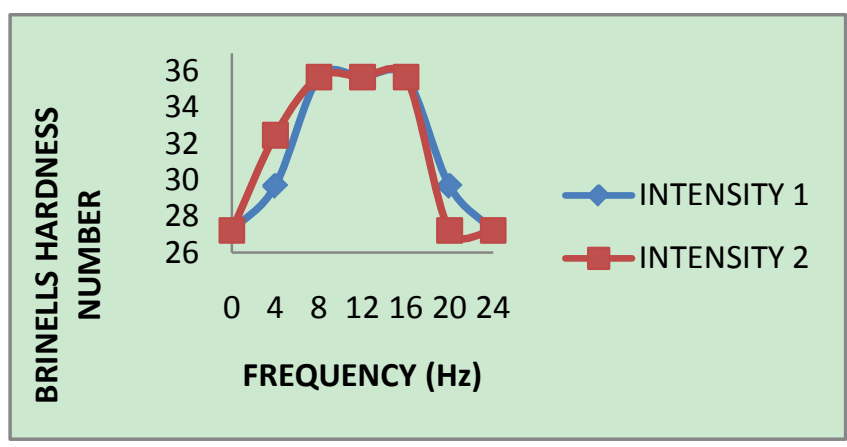

Figure 3. Effects of Frequency of vibration on the Hardness of the samples

These could be explained that the structures of the $\mathrm{Mg}-\mathrm{Al}-\mathrm{Zn}$ alloys consist of a solid solution and the intermetallic compound $\mathrm{Mg}_{17} \mathrm{Al}_{12}$ ( $\beta$ phase) at the grain boundaries the quantity and character of these intermetallic compounds greatly influence the pouring characteristics and mechanical properties of the component. Intermetallic compounds affect the plasticity of the alloys in a semi-solid and solid state[16]. The compound $\mathrm{Mg}_{17} \mathrm{Al}_{12}$, as the phase solidifying last, fills interdendritic cavities and thus influenc es flowability, shrinkage, porosity, and the development of cracks,[17]. The strength and elasticity properties of the alloys depend on the character of the intermetallic phases (unbroken lattice, individual, globular inclusions or tapering and angular inclusions at the triangular junctions) and their quantity in the matrix. It was found that inside a grain the creep resistance is lower than at the grain boundary. At the grain boundaries discontinuous precipitations are formed that contribute to the creep-deformation process, $[18,19]$. The vibration of the melt during solidification built up forced convection within the melt which imparted relatively uniform temperature in every part of the solidifying melt; as the latent heat is being conducted away through the wall of the mould the temperature of the melt is equalized by the forced convection brought about by the vibration. The effect of this could be likened to annealing a steel sample and allowing it to cool in the furnace to refine the grain structure and remove the mechanical strain set up during solidification[14].

The effect of vibration of the melt during solidification increases with increase in the frequency of vibration and the intensity of vibration up to between 12 to $16 \mathrm{~Hz}$; subsequent increase in frequency of vibration results in the reduction of the UTS, percentage elongation and absorbed energy.

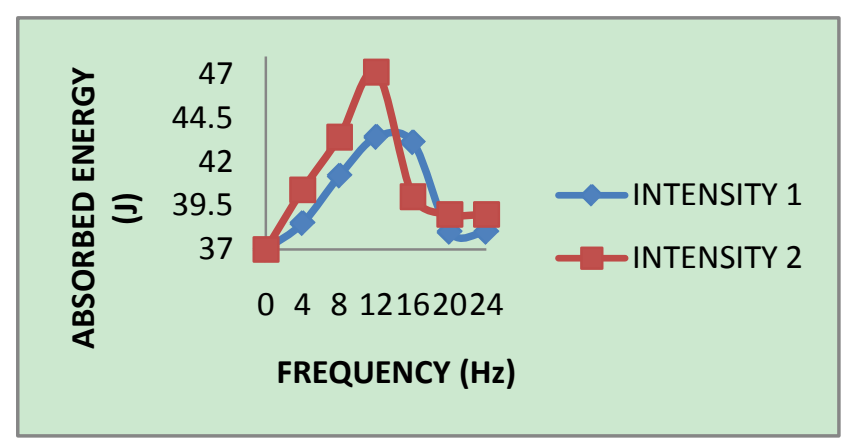

Figure 4. Effects of Frequency of vibration on the Impact Strength of the samples

Figure 4 shows the effects of the frequency (and intensity) of vibration on the impact (energy absorbed) strength of the samples. It is observable from the figure that the absorbed energy of the sample increases with the frequency of vibration; the absorbed energy reaches the maximum at around $12 \mathrm{~Hz}$ and then begins to decrease. It is also conspicuous that the intensity 2 has the higher value of absorbed energy between 0 and $12 \mathrm{~Hz}$ and 20 and $24 \mathrm{~Hz}$, but lower value between 12 and $16 \mathrm{~Hz}$. The higher the intensity of mould vibration during solidification of molten metal the higher will be the toughness of the subsequent sample produced. The continuous precipitations inhibit the dislocati on movement, while the discontinuous precipitations create boundary surfaces where dislocations can be developed and annihilated. In all the cases the intermetallic phases disperse in the vicinity of the grain boundaries and affect creep by impeding sliding and dislocation movements at the grain boundaries. The shape and distribution of the intermetallic phases formed are of great importance with regard to the mechanical properties. Small, non-spherical precipitations are preferable, whereas coarse and block-shaped particles affect these properties negatively,[18]. 


\section{Conclusions}

Increased frequency of mould vibration during solidification causes refinement of the grain in the alloy. This refinement of the grains results in an increased ductility/ percentage elongation/UTS/impact strength and hardness of the said alloy samples. Increase in vibration intensities results in higher maximum values of these mechanical properties. The mechanical mould vibrations increasingly improve the mechanical properties of the alloy, with the optimum mechanical properties occurring at a frequency of $12 \mathrm{~Hz}$. A moderate application of this optimum frequency of mould vibration during alloy solidification in foundry will improve workability of the alloy for all applications involving plastic deformation of the cast alloy without necessarily subjecting it to annealing.

\section{ACKNOWLEDGEMENTS}

The authors would like to acknowledge the assistance rendered by $\mathrm{Mr}$ Alo F.I., $\mathrm{Mr}$ Aminu, $\mathrm{Mr}$ Omolayo, $\mathrm{Mr}$ Olaoye and Mr Solanke, (all of the Department of Materials Science and Engineering, O.A.U., Ile-Ife) during the bench work of this research.

\section{REFERENCES}

[1] Valiev, R.Z., Islamgaliev, R.K. and Alexandrov, I.V.,Bulk nanostructured materials from severe plastic deformation. Progress Mater. Sc. 45, 103-189, 2000.

[2] Markushev, M.V., Bampton, C.C., Murashkin, M.Y. and Hardwick, D.A., Structure and properties of ultra-fine grained aluminum alloys produced by severe plastic deformation Mater. Sc. Eng. A234, 927-931, 1997.

[3] S. Lee, M. Furukawa, Z. Horita and T.G. Langdon, "Developing a Superplastic Forming Capability in a Commercial Aluminum Alloy Without Scandium or Zirconium Additions," Materials Science and Engineering A342, 294-301 (2003).

[4] S. Komura, Z. Horita, M. Furukawa, M. Nemoto and T.G. Langdon: An Evaluation of the Flow Behavior during High Strain Rate Superplasticity in an Al-Mg-Sc Alloy, Metall. Mater. Trans. A 32A (2001) 707-716

[5] Flemings, M.C.; Behavior of Metal Alloys in the Semi-Solid State, Metall. Trans. B, 22B, 269, 1991.
[6] Vives, C.; Elaboration of semisolid alloys by means of new rheocasting processes Metall. Trans. B, 24B, 493, 1993.

[7] Belyakov, A., Miura, H. and Sakai, T.; Fine-Grained Structure Formation in Austenitic Stainless Steel under Multiple Deformation at $0.5 \mathrm{Tm}$, Materials Transaction. JIM 41 476-484, 2000.

[8] Saito, Y., Utsunomiya, H., Tsuji, N. and Sakai, T. Novel Ultrahigh Straining Process for Bulk Materials-Development of the Accumulative Roll-Bonding (ARB)Process, Acta Mater., 47, 579-583, 1999.

[9] Alexandre, G., Olegi, S., Taku, S., Rustam, K. and Hiromi, M.; "Grain Refinement in As-Cast 7475 Aluminium alloy under Hot Equal-Channel Angular Pressing Mater. Trans. 44(4), 766-774, 2003.

[10] Dragnevski, K., Cochrane, R.F. and Mullis, A.M., Experimental Evidence for Dendritic Tip Splitting in Deeply Undercooled, Ultra-High Purity $\mathrm{Cu}$. Physical Review Letters, 89, 215502, 2002.

[11] Vives, C.; Grain Refinement in Aluminium Alloys by means of Electromagnetic Vibrations including Cavitation Phenomena, JOM-e, 50 (2), 1-9, 1998.

[12] Mollard, F.R., Flemings, M.C. and Niyama, E.F. ; “Alumium Fluidity in Casting”, J. Met., 39 (11), 34, 1987.

[13] Abramov, O.; Ultrasound in Liquid and Solid Metals, CRC Press, Boca Raton, 289, 1994.

[14] Higgins, R.A.; Engineering Metallurgy Part 1: Applied Physical Metallurgy, 5th Edition, ELBS with Edward Arnold, Kent, Pp261, 376, 1991.

[15] Vives, C.; Elaboration of semisolid alloys by means of new rheocasting processes", Met. and Mat. Trans. B 23B, 189-206, 1992.

[16] Goryany, V. and Mauk, P.J.; Intermetallic Compounds and Choice of Alloying Elements for the Manufacture of Thixomolded Creep resistant Magnesium Alloys; Journal of Mining and Metallurgy, 43 B, Pp 85 - 97, 2007.

[17] Nikulin, L.V., Lip?in, T.N. and Zaslavskij, M.L.; Die casting of magnesium alloys. Mašinostroenie, Moscow, (in Russian), 1978.

[18] Pettersen, K., Bakke, P., Skar, J.I., Tian, Ch. and Albright, D.; Druckguss-Praxis 4, str, pp. 115-121 (in German), 2004.

[19] Dargusch, M.S. Pettersen, K. and Dunlop, G.L.; The Microstructure and Creep Behaviour of Die Cast Magnesium AZ91 and AS21 Alloys. Proc. 19th Int. Die Casting Congress, Minneapolis, USA, pp131-137, Nov, 1997. 